\title{
Analysis of Thoracic Spine Thrust Manipulation for Reducing Neck Pain
}

\author{
Luiz Alfredo Braun Ferreira ${ }^{1,2)}$, Lucas Cristiano Fath Santos ${ }^{1)}$, \\ Wagner Menna Pereira ${ }^{1)}$, Hugo Pasini Neto ${ }^{2}$, Luanda André College Grecco ${ }^{3)}$, \\ Thaluanna Calil Lourenço Christovão ${ }^{3)}$, Claudia Santos Oliveira ${ }^{3)}$ \\ 1) Department of Physical Therapy, Guairacá College \\ 2) Doctoral Program in Rehabilitation Sciences, Nove de Julho University \\ 3) Master's Program in Rehabilitation Sciences, Nove de Julho University: São Paulo, SP, Brazil. \\ E-mail:csantos@uninove.br
}

\begin{abstract}
Purpose] The cervical spine is a common site of pain, which may arise from different parts of the upper limbs or dysfunctions of the upper thoracic spine. The different sections of the spinal column are interlinked, and one region exerts an influence over another. Thus, a low range of motion (hypomobility) in the thoracic spine is an indicator of neck pain, and alterations in the cervical spine can occur due to dysfunctions of the thoracic region. The aim of the present study was to assess the efficacy of upper thoracic spine (T1-T4) thrust manipulation with regard to reduction of pain and disability in patients with neck pain. [Subjects and Methods] Twenty-five individuals with persistent neck pain upon movement participated in this study. The individuals were evaluated using the Neck Disability Index and a visual analog scale for pain. Each individual underwent five sessions of thoracic spine thrust manipulation. Data analysis involved the Student's t-test. [Results] Significant improvements were found in neck pain and disability. [Conclusion] Based on the results of the present study, thoracic spine thrust manipulation proved effective in the treatment of individuals with neck pain, leading to a reduction in both pain and disability.

Key words: Neck pain, Thoracic spine thrust manipulation
\end{abstract}

(This article was submitted Sep. 27, 2012, and was accepted Nov. 7, 2012)

\section{INTRODUCTION}

Neck pain is a common symptom in adults. A large portion the population experiences neck pain at some time in life, with prevalence rates ranging from $30 \%$ to $50 \%{ }^{1)}$. Moreover, costs related to this symptom have increased considerably ${ }^{2}$.

Neck pain is classified based on underlying health problems and emerges in the form of reduced mobility, cervical pain with headache, cervical pain with impaired coordinated movements and irradiating cervical pain. Neck pain related to deficient mobility may be caused by the mobility of different joints, upper arm pain, thoracic pain, the resistance of isolated muscles, ligaments and fascia and certain activities of daily living (driving, swimming, household chores or lying down) ${ }^{3}$.

The cervical spine is a common site of pain that may arise from different parts of the upper limbs or dysfunctions of the upper thoracic spine ${ }^{4}$. As the different sections of the spinal column are interlinked and one region exerts an influence over another, a low range of motion (hypomobility) in the thoracic spine is an indicator of neck pain, and alterations in the cervical spine can occur due to dysfunctions of the thoracic spine ${ }^{5,6)}$.

Treatment of the spinal column and soft tissues in cases of neck pain is performed by physiotherapists, osteopaths and chiropractors ${ }^{7}$. According to Chaitow $^{8)}$, osteopathic medicine is a health field that treats the body as a whole, with the belief that any alteration in the musculoskeletal system can affect other functions. The author also describes the self-healing of the body, which is capable of maintaining homeostasis, but this process is dependent on both intrinsic and extrinsic factors. Osteopathic medicine is a method of treatment that employs manipulation techniques for the assessment and correction of mechanical deficiencies in the body.

When a joint is unable to perform its normal functional movements, it is characterized as hypomobile. For maintenance of the functionality of the body, a compensatory movement (characterized as hypermobile) is required. While a hypomobile structure is asymptomatic, excessive compensatory movements often overload the structure, leading to pain $^{9}$. Treatment of hypomobility should be performed with the technique referred to as thrust, the aim of which is to correct the biomechanics, leading to an increase in the range of motion and muscle tone and a reduction in pain ${ }^{10)}$. Thrust is a thoracic manipulation technique that applies a movement of high velocity and low amplitude to a joint. This procedure may generate a cavitation, which is an indication that the movement has been performed successfully. The method is called by different names: adjustment, high-velocity thrust, mobilization with impulse and grade $\mathrm{V}$ 
mobilization. Training is necessary, and the method requires more precision than strength ${ }^{10-12)}$.

The risk-benefit ratio with regard to manipulation of the cervical spine should be evaluated, as this procedure has been associated with mild to moderate adverse effects and serious adverse effects related to the vertebral artery ${ }^{13)}$. To avoid such problems, mobilization and manipulation of another region of the spinal column, such as the thoracic spine, have been employed instead of cervical manipulation ${ }^{7)}$. Thrust for correction of the thoracic vertebrae may be carried out by employing different techniques, such as lift off (upper thoracic and lower thoracic spine), thoracic rotation manipulation, the "dog" technique (upper thoracic and lower thoracic spine) and the crossed pisiform technique ${ }^{14)}$. Thrust eliminates tissue resistance, and the vertebra is induced to its articular limit in the opposite direction of the injury; at the beginning of exhalation, the vertebra is corrected with a high-velocity, low-amplitude movement ${ }^{11)}$.

Chiradejnant et al. ${ }^{15)}$ conducted a study on the effectiveness of application of joint mobilization in individuals with low back pain with respect to pain and range of motion. They showed no significant difference between application of the technique at the level of the lumbar pain or at levels with no pain previously selected by a therapist. One explanation for this was that joint mobilization has a central hypoalgesic effect, so the technique does not necessarily need to be performed on the affected segment.

Cleland et al. ${ }^{16)}$ reported that an intervention often used by physiotherapists in the treatment of neck pain is the manipulation of the thoracic spine. In their study, thoracic manipulative treatment was performed in association with exercise in 140 patients, who were then evaluated by NDI at 1 week, 4 weeks and 6 months after treatment. The results of their study showed that patients with mechanical neck pain who received thoracic spine manipulation and exercise exhibited significantly greater improvement in cervical disability. A recently published guideline for the treatment of patients with throat pain recommends use of thoracic spine manipulation impulse in the management of this population $^{17)}$

There are a number of ways to assess dysfunctions of the cervical spine for the determination of more effective treatment. The NDI is the most widely used condition-specific disability scale for patients with neck pain and consists of 10 items addressing different aspects of function, each scored from 0 to 5, with a maximum score of 50 points. Higher scores represent increased levels of disability. The NDI has been reported to be a reliable and valid outcome measure for patients with neck pain ${ }^{16}$ ). Another form of measurement of pain is the patient's visual analogue pain scale (VAS). According to Cleland et al. ${ }^{18)}$ and Fernandes-de-las-penas et al. ${ }^{19)}$, the VAS is a reliable and valid instrument to assess pain intensity and was selected as the outcome measure based on its ability to detect immediate changes in pain.

The aim of the present study was to assess the efficacy of thoracic spine thrust manipulation for the relief of neck pain as analyzed using the Neck Disability Index and a visual analogue scale.
Table 1. Mean \pm standard deviation of anthropometric characteristics of participants

\begin{tabular}{lcccc}
\hline \multicolumn{5}{c}{ Anthropometric variables } \\
\hline & $\begin{array}{c}\text { Age } \\
(\text { Years })\end{array}$ & $\begin{array}{c}\text { Stature } \\
(\mathrm{m})\end{array}$ & $\begin{array}{c}\text { Weight } \\
(\mathrm{kg})\end{array}$ & $\begin{array}{c}\text { BMI } \\
\left(\mathrm{kg} / \mathrm{m}^{2}\right)\end{array}$ \\
\hline Mean & 21.8 & 1.66 & 60.12 & 21.86 \\
Standard Deviation & 3.055 & 0.069 & 13.79 & 4.57 \\
\hline
\end{tabular}

\section{SUBJECTS AND METHODS}

An experimental clinical trial was carried out at the Motor Control Laboratory of Guairacá College, Guarapuava, Paraná, Brazil. This study received approval from the Human Research Ethics Committee of the Central-Western State University (Brazil) under protocol number 141/2011 in compliance with Resolution 196/96 of the Brazilian National Board of Health. All volunteers were informed with regard to the objectives and procedures of the study and agreed to participate by signing a statement of informed consent.

Thirty-five volunteers filled out the NDI, but three did not achieve the minimum score of $10 \%$ for inclusion, and seven decided not to participate. Thus, 25 adult volunteers ( 2 men and 23 women) participated in the study. Age ranged from 18 to 30 years (mean: $21.8 \pm 3$ years). Mean height was $166 \pm 0.6 \mathrm{~cm}$, mean body mass was $60.12 \pm 13 \mathrm{Kg}$ and mean body mass index (BMI) was $21.8 \pm 4 \mathrm{Kg} / \mathrm{m}^{2}$. BMI was based on the equation proposed by the Diet, Nutrition and the Prevention of Chronic Diseases publication issued by the World Health Organization ${ }^{20}$ (Table 1).

The inclusion criteria were age between 18 and 30 years, either gender and pain in the cervical region during neck movements (flexion-extension, rotation and lateral inclination). The following were the exclusion criteria: score below 5 points $(10 \%)$ on the NDI, symptoms of bone weakness due to tumor, infection, congenital condition or trauma, neurological impairment, history of whiplash, vascular conditions (vertebrobasilar insufficiency and aneurysm), pregnancy and non-consent for participation $6,10,21)$.

The patients included in the study underwent treatment consisting of five sessions of thrust, which were performed in a treatment period of fifteen days, and then one session every three days. The NDI and VAS were administered during every session. For assessment of the acute effect of thrust, the VAS was administered before and after upper thoracic manipulation (T1 to $\mathrm{T} 4$ ) in the second, third and fourth sessions. Thoracic spine thrust manipulation was performed in the first four sessions.

According to the Motor Accident Insurance Commission (2011) of Australia ${ }^{22)}$, the Neck Disability Index (NDI) can detect a 5 point (10\%) change in neck pain with a $90 \%$ confidence interval. The NDI is an important assessment tool for measuring the extent to which neck pain affects the performance of activities of daily living. This index is made up of 10 questions, each with six response options ranging from 0 to 5 points. Thus, the total score ranges from 0 to 50 points, with higher scores denoting greater disability. The 
Table 2. Mean \pm standard deviation and statistical significance of the values of visual analog scale of pain (VAS) and Neck Disability Index questionnaire (NDI) analyzed in subjects who received 5 treatment sessions

\begin{tabular}{ccc}
\hline & $\begin{array}{c}\text { Mean } \pm \text { standard deviation of } \\
\text { VAS }\end{array}$ & $\begin{array}{c}\text { Mean } \pm \text { standard deviation of } \\
\text { NDI }\end{array}$ \\
\hline Session 1 & $4.14 \pm 1.7$ & $9.76 \pm 3.4$ \\
Session 2 & $1.96 \pm 1.8^{*}$ & $7.64 \pm 3.0^{*}$ \\
Session 3 & $1.64 \pm 1.8$ & $6.36 \pm 3.5^{*}$ \\
Session 4 & $0.82 \pm 1.2^{*}$ & $5.44 \pm 3.5^{*}$ \\
Session 5 & $1.44 \pm 2.1$ & $4.44 \pm 3.9^{*}$ \\
$* \mathrm{p}<0.05$ & &
\end{tabular}

questionnaire is divided into three categories (pain, daily activities and attention) and has been used in a number of studies involving patients with neck pain ${ }^{18,21)}$.

A visual analog scale (VAS) can also be employed to measure patient pain and determine the efficacy of treatment over time. The patient is shown a scale ranging from 0 (absence of pain) to 10 (unbearable pain), on which he/she places a mark corresponding to his/her current level of pain. This scale was used in the study carried out by Krauss et al. ${ }^{23)}$.

Thoracic manipulation was performed using the "dog" or "pistol-grip" technique. According to the model recently proposed by Mintken et al. ${ }^{24)}$, thrust manipulation can be described as a high-velocity, end-range, anterior-posterior force applied through the elbows to the upper thoracic spine on the midthoracic spine in cervicothoracic flexion. This technique was performed with the patient in a supine position. The therapist used his or her manipulative hand to stabilize the inferior vertebra of the motion segment targeted and used his or her body to push down through the patient's arms to perform a high-velocity, low amplitude thrust.

Descriptive and inferential statistics were performed using SPSS for Windows 16.0. The Shapiro-Wilk test was employed to determine the normality of the data. The Student's t-test was used for analysis of parametric data, and the Wilcoxon test was used for nonparametric data. The level of significance on all statistical tests was set to $5 \%(\mathrm{p} \leq 0.05)$. The results of the NDI and VAS for neck pain before and after thoracic manipulation are expressed as the mean and standard error.

\section{RESULTS}

An approximately $65 \%$ reduction in pain was found between the first and final VAS scores (4.14 and 1.44 points, respectively). Moreover, a gradual reduction in pain was observed throughout the sessions. In the analysis of the acute effect of thoracic manipulation, a significant reduction in neck pain was found immediately following administration of the thrust technique $(\mathrm{p}<0.001)$.

The mean NDI scores were 9.76 (19.52\%), 7.64 (15.28\%), 6.36 (12.72\%), $5.44(10.88 \%)$ and $4.44(8.88 \%)$ in sessions 1 through 5, respectively. A statistically significant reduction in NDI score was found at the end of the sessions $(\mathrm{p}<0.0001)$. Approximately $54.5 \%$ of the reduction in disability (5.32 points or $10.64 \%$ ) occurred between the first and last session, and approximately $40 \%$ of the reduction in disability ( 2.12 points or $4.24 \%$ ) occurred after manipulation in the first session. Statistically significant differences were found in the NDI score before and after the five sessions of thoracic manipulation $(\mathrm{p}<0.0001)$ (Table 2).

\section{DISCUSSION}

In the present study, statistically significant improvements were found in both the NDI and VAS for neck pain. However, the significant improvement in pain reported by the patients only occurred after the second session of thoracic manipulation.

Manual therapy generates a hypoalgesic effect and causes excitation of the sympathetic nervous system ${ }^{25)}$. Muscle activity is reported to increase after a single manipulation of a particular site of the spinal column, with greater resistance to fatigue in the corresponding muscle ${ }^{26)}$. According to Gibbons and Tehan ${ }^{10)}$, thrust leads to a reduction in tonus and improved range of motion in a zygapophyseal joint. According Couto ${ }^{27)}$, the significant feature of joint manipulation in clinical practice is its immediate effect on the change in pain threshold. Wright et al. ${ }^{28)}$ observed a degree of hypoalgesia in a period of seconds to minutes after application of this technique. According to them, the descending noradrenergic system acts on the spinal cord and inhibits the release of $\mathrm{P}$ substance, stimulating the release of endogenous opioids in the spinal cord.

A review by Gross et al. ${ }^{29)}$ using 33 studies concluded that mobilization and/or manipulation, when used with exercise, are beneficial for persistent mechanical neck disorders with or without headache. Walker et al. ${ }^{30)}$ conducted a study to analyze the effectiveness of manual therapy and exercise for neck pain, and it can be seen that a program of manual therapy and exercise for neck pain resulted in clinically and statistically significant improvement in the short and long term, especially in issues such as pain, disability, and perceived recovery of the patient, when compared with a counseling program for patients, isolated mobility exercises and therapeutic ultrasound.

In a randomized controlled clinical study conducted by Hoving et al. ${ }^{31)}$ in order to verify the effectiveness of manual 
therapy in patients with neck pain compared with physical therapy and medication, 183 patients were followed, and it was concluded that manual therapy achieved a statistically significant difference $(p=0.02)$ compared the other treatments in the first 7 weeks of monitoring.

In a randomized study carried out by Cleland et al. ${ }^{18)}$, the group having received thrust manipulation achieved immediate improvements in pain compared with a group that received placebo manipulation. The NDI was only used at the beginning of the study to determine disability in the two groups (33.6\% in the placebo group and $28.4 \%$ in the thrust group). The score of the visual employed (scores ranging from 0 to 100) was 41.6 in the thrust group and dropped to 26.1 immediately following manipulation. In the present study, the VAS was not administered immediately following the first session of manipulation. However, VAS scores in the subsequent sessions revealed statistically significant reductions in pain immediately following thoracic manipulation, which is in agreement with the findings described in the above study.

In a comparative study of two sessions of either upper and middle thoracic manipulation or mobilization (grades III and IV), the group submitted to manipulation achieved a mean reduction of $15.5 \%$ in the NDI (final score: $18 \%$ ) and a mean reduction of 2.6 points on the VAS (mean final score: 2.7 points). In the second session, which was held two to four days after the first, only the questionnaires were applied ${ }^{6}$. In the present study, the mean reduction in NDI between the first and second sessions was $4.2 \%$. This difference may have been due to the fact that thrust manipulation was only performed on the upper thorax and the initial NDI was lower in comparison to the with the above study.

In a study carried out by Cleland et al. ${ }^{21)}$, six thoracic manipulations (upper and middle) were performed in up to three sessions. The group for which manipulation was successful experienced greater improvements in pain (VAS $=2.2$ ) and disability (NDI $=18.6 \%$ ) in comparison with the group that did not achieve success with manipulation. In agreement with these findings, the volunteers in the present study reported a significant improvement in pain and achieved a significant improvement in NDI scores after five sessions of thoracic manipulation.

In a comparative study carried out by Fernandez-delas-Penas et al. ${ }^{19)}$, a control group received five sessions of electrothermal therapy, and an experimental group received both electrothermal therapy and thoracic manipulation. The groups submitted to manipulation achieved lower pain scores in the first session (acute effect of manipulation: $25 \%$ reduction in pain) as well as after five sessions $(63 \%$ accumulated reduction in pain), thereby demonstrating the efficacy of this technique in both the short and long terms. In agreement with these findings, the present study demonstrated a reduction in pain immediately following manipulation as well as after five sessions of manipulation. In both studies, the reduction in pain immediately following manipulation was not maintained in the subsequent session, but the VAS score prior to the subsequent manipulation was lower than that prior to the previous session. Dishiman and Bulbulian $^{32)}$ concluded that manipulation and mobilization of the spinal column may cause short-term inhibitory effects of the motor system, but these effects are transitory, which may explain the reduction in pain immediately following manipulation.

In a study by Cleland et al. ${ }^{16)}$, one group was submitted to an exercise program and thoracic manipulation, and another group was submitted to the exercise program alone in five sessions over the course of four weeks. The group submitted to both manipulation and exercise demonstrated greater improvements in disability (initial NDI $=30$ NDI in Week $1=16$ NDI in Week $4=10$ and NDI after six months $=8$ ) than the group submitted to exercise alone (initial NDI $=$ 29 NDI in Week $1=18$ NDI in Week $4=15$ and NDI after six months $=13$ ). However, the experimental group only achieved a significant improvement in VAS scores (initial $\mathrm{VAS}=4.4 \mathrm{VAS}$ in Week $1=2.3 \mathrm{VAS}$ in Week $4=1.8 \mathrm{VAS}$ after 6 months $=1.5$ ) after the first session in comparison with the control group (initial VAS $=4$ VAS in Week $1=$ 3.2 VAS in Week $4=2.0$ VAS after 6 months $=1.8$ ). In the present study, significant improvements were found in both the NDI and VAS scores in all sessions, but pain intensity was not assessed after the five sessions.

In a study carried out by Lau, Chiu and $\mathrm{Lam}^{33}$, the intervention group was submitted to thoracic spine manipulation, infrared radiation therapy and a program of orientation and cervical exercises in eight sessions held over four weeks, whereas the control group was submitted to infrared radiation therapy and the orientation program. A greater reduction in pain was found in the group submitted to thoracic spine manipulation, with a mean initial VAS of 5.02, immediate posttreatment VAS of 3.14, VAS three months after treatment of 3.29 and VAS six months after treatment of 2.98 .

Following thoracic spine manipulation, Fernandezde-las-Penas et al. ${ }^{34)}$ found a reduction in neck pain and a tendency toward an increase in cervical range of motion in a single session. The NDI was only employed as an inclusion criterion (mean score: 14.4). The VAS score was significantly reduced from an initial score of 5.5 to 2.9 immediately following manipulation and was 2.7 after 48 hours. In the present study, a greater reduction in NDI was found after each session in comparison with the first session, and a significant reduction in pain was found as well.

Manipulation of the upper thorax (T1 to T4) in patients with persistent neck pain upon movement led to an improvement in cervical rotation among all subjects, who also reported improvement in pain following manipulation. Thus, thrust thoracic manipulation may be considered an effective treatment for cervical movement deficiency ${ }^{23)}$. Yip et al. ${ }^{35)}$ measured the craniocervical angle in individuals with neck pain and found that this angle was diminished in accordance with pain severity and neck disability in comparison with individuals without neck pain. Thoracic spine manipulation may reduce mechanical stress in the cervical spine, consequently improving chronic neck pain ${ }^{33)}$ and reducing the degree of disability ${ }^{3}$. This procedure may also be an adequate method for the treatment of cervical dysfunctions either alone or as a complement to other procedures ${ }^{6,21)}$.

The results of the present study demonstrate that high- 
speed, low-amplitude thrust manipulation of the upper thoracic spine ( $\mathrm{T} 1$ to $\mathrm{T} 4)$ is an effective treatment for reduction of neck pain upon movement and neck disability, as measured by a visual analog scale and the Neck Disability Index. This method can be employed in combination with other treatment modalities, such as an exercise program and instructions to the patient to maintain analgesia, for improvement in the quality of life of patients with neck pain and disability. Further studies should be carried out combining thoracic spine thrust manipulation with other techniques and measuring both the acute and long-term effects of this technique.

\section{REFERENCES}

1) Hogg-Johnson S, Van der Velde G, Carroll LJ, et al.: The burden and eeterminants of neck pain in the general population. Eur Spine J, 2008, 17: 39-51. [CrossRef]

2) Martin BI, Deyo RA, Mirza SK, et al.: Expenditures and health status among adults with back and neck problems. JAMA, 2008, 299: 656-664. [Medline] [CrossRef]

3) Childs JD, Cleland JA, Elliott JM, et al.: Neck pain: clinical practice guide lines linked to the international classification of functioning, disability, and health from the orthopaedic section of the American Physical Therapy Association. J Orthop Sports Phys Ther, 2008, 38: 1-67.

4) Dutton M: Orthopaedic Physical Therapy: Examination, Evaluation and Intervention. 2nd ed., Porto Alegre: Artmed, 2010.

5) Lau HMC, Chiu TTW, Lam TH: The effectiveness of thoracic manipulation on patients with chronic mechanical neck pain: a randomized controlled trial. Man Ther, 2011, 16: 141-147. [Medline] [CrossRef]

6) Cleland JA, Childs JD, Fritz JM, et al.: Development of a clinical prediction rule for guiding treatment of a subgroup of patients with neck pain: use of thoracic spine manipulation, exercise, and patient education. Phys Ther, 2007, 87: 9-23. [Medline] [CrossRef]

7) Carlesso LC, Gross AR, Santaquida PL, et al.: Adverse events associated with the use of cervical manipulation and mobilization for the treatment of neck pain in adults: a systematic review. Man Ther, 2010, 15: 434-444. [Medline] [CrossRef]

8) Chaitow L: Osteopathy: Handling and Body Structure. $1^{a}$ ed., São Paulo: Summus, 1990

9) Oliveira JPL, Oliveira LCA: Analysis of the effects of the chiropractic adjustment in the cervical spine in patients with neck pain. FARN Magazine, 2009, 8: 37-54.

10) Gibbons P, Tehan P: Spinal manipulation: indications, risks and benefits. J Bodywork and Mov Ther, 2001, 5: 110-119. [CrossRef]

11) Bienfait M: Bases elementary: manual therapy technical and osteopathy 1st ed., São Paulo: Summus, 1997.

12) Evans DW: Mechanisms and effects of spinal high-velocity, low-amplitude thrust manipulation: previous theories. J Manipulative Physiol Ther, 2002 25: 251-262. [Medline] [CrossRef]

13) Ernst E: Adverse effects of spinal manipulation: a systematic review. J R Soc Med, 2007, 100: 330-338. [Medline] [CrossRef]

14) Ricard F, Sallé JL: Treaty of Osteopathy. 3rd ed., Madrid: Publisher Panamericana, 2010.

15) Chiradejnant A, Maher GC, Hatermer J, Stepkovitch N: Efficacy of "therapist-sellected" versus "randomly sellected" mobilization techniques for the treatment of low back pain: a randomized controlled trial Australian Journal of Physiotherapy, 2003, 49: 233-241. [Medline]

16) Cleland JA, Mintken PE, Carpenter K, et al.: Examination of a clinica prediction rule to identify patients with neck pain likely to benefit from thoracic spine thrust manipulation and a general cervical range of motion exercise: multi-center randomized clinical trial. Phys Ther, 2010, 90:
1239-1250. [Medline] [CrossRef]

17) Childs JD, Cleland JA, Elliott JM et al.: Neck pain: clinical practice guidelines linked to the international classification of functioning, disability and health from the orthopedic section of the American Physical Therapy Association. J Orthop Sports Phys Ther, 2008, 38: A1-A34. [Medline]

18) Cleland JA, Childs JD, McRae M, et al.: Immediate effects of thoracic manipulation in patients with neck pain: a randomized clinical trial. Man Ther, 2005, 10: 127-135. [Medline] [CrossRef]

19) Fernandez-de-las-penas C, Cleland JÁ, Huijbregts P, et al.: Repated applications of thoracic spine thrust manipulation do not lead to tolerance in patients presenting acute mechanical neck pain: a secondary analysis. J Man \& Manip Ther, 2009, 3: 154-162.

20) World Health Organization: Diet, nutrition and prevention of chronic diseases. Geneva, 2003.

21) Cleland, JA, Glynn P, Whitman JM, et al.: Short-term effects of thrust versus nonthrust mobilization and manipulation directed at the thoracic spine in patients with neck pain: a randomized clinical trial. Phys Ther, 2007, 87: 431-440. [Medline] [CrossRef]

22) Motor Accident Insurance Commission: Neck Disability Index. Available from: http://www.maic.qld.gov.au/forms-publications-stats/pdfs/NDI.pdf. (Accessed: May 25, 2011).

23) Krauss J, Creighton D, Ely JD, et al.: The immediate effects of upper thoracic translatoric spinal manipulation on cervical pain and range of motion: A randomized clinical trial. J Man Manip Ther, 2008, 16: 93-99. [Medline]

24) Mintken PE, DeRosa C, Little T, et al.: AAOMPT clinical guidelines: a model for standardizing manipulation terminology in physical therapy practice. J Orthop Sports Phys Ther, 2008, 38: A1-A6. [Medline]

25) Vicenzino B, Collins B, Benson H, et al.: An investigation of the interrelationship between manipulative therapy-induced hypoalgesia and sympathoexcitation. J Manipulative Physiol Ther, 1998, 21: 448-453. [Medline]

26) de Camargo VM, Albuquerque-Sendín F, Bérzin F, et al.: Immediate effects on electromyographic activity and pressure pain thresholds after a cervical manipulation in mechanical neck pain: a randomized controlled trial. J Manipulative Physiol Ther, 2011, 34: 211-220. [Medline] [CrossRef]

27) Couto IBVL: Efeito agudo da manipulação em pacientes com dor lombar crônica: estudo piloto. Rev Fisio Mov, 2007, 20: 57-62.

28) Wright A, Mayer T, Gatchel R: Outcomes of disabling cervical spine disorders in compensation injuries: a prospective comparison to tertiary rehabilitation response for chronic lumbar disorders. Spine, 1999, 24 178-183. [Medline] [CrossRef]

29) Gross AR, Hoving JL, Haines TA, et al.: A Cochrane review of manipulation and mobilization for mechanical neck disorders. Spine, 2004, 29: 1541-1548. [Medline] [CrossRef]

30) Walker MJ, Boyles RE, Young BA, et al.: The effectiveness of manual physical therapy and exercise for mechanical neck pain: a randomized clinical trial. Spine, 2008, 33: 2371-2378. [Medline] [CrossRef]

31) Hoving JL, De Vet HC, Koes BW, et al.: Manual therapy, physical therapy, or continued care by the general practitioner for patients with neck pain long-term results from a pragmatic randomized clinical trial. Clin J Pain, 2006, 22: 370-377. [Medline] [CrossRef]

32) Dishman JD, Bulbulian R: Spinal reflex attenuation associated with spinal manipulation. Spine, 2000, 25: 2519-2524. [Medline] [CrossRef]

33) Lau KT, Cheunq KY, Chan KB, et al.: Relationships between sagittal postures of thoracic and cervical spine, presence of neck pain, neck pain severity and disability. Man Ther, 2010, 15: 457-462. [Medline] [CrossRef]

34) Fernández-de-las-Peñas C, Palomeque-del-Cerro L, Rodriguez-Blanco $\mathrm{C}$, et al.: Changes in neck pain and active range of motion after a single thoracic spine manipulation in subjects presenting with mechanical neck pain: a case series. J Manipulative Physiol Ther, 2007, 30: 312-320. [Medline] [CrossRef]

35) Yip CH, Chiu TT, Poon AT: The relationship between head posture and severity and disability of patients with neck pain. Man Ther, 2008, 13: 148-154. [Medline] [CrossRef] 